\title{
Novel constant-pressure irrigation technique for the treatment of renal pelvic tumors after ipsilateral ureterectomy.
}

\section{$\operatorname{AUTHOR}(\mathrm{S}):$}

Nakamura, Kenji; Terada, Naoki; Sugino, Yoshio; Yamasaki, Toshinori; Matsui, Yoshiyuki; Imamura, Masaaki; Okubo, Kazutoshi; Kamba, Tomomi; Yoshimura, Koji; Ogawa, Osamu

\section{CITATION:}

Nakamura, Kenji ... [et al]. Novel constant-pressure irrigation technique for the treatment of renal pelvic tumors after ipsilateral ureterectomy.. International journal of urology 2014, 21(6): 617-618

\section{ISSUE DATE:}

2014-06

URL:

http://hdl.handle.net/2433/199612

\section{RIGHT:}

This is the peer reviewed version of the following article: Nakamura, K., Terada, N., Sugino, Y., Yamasaki, T., Matsui, Y. Imamura, M., Okubo, K., Kamba, T., Yoshimura, K. and Ogawa, O. (2014), Novel constant-pressure irrigation technique for the treatment of renal pelvic tumors after ipsilateral ureterectomy. International Journal of Urology, 21: 617-618, which has been published in final form at http://dx.doi.org/10.1111/iju.12386. This article may be used for noncommercial purposes in accordance with Wiley Terms and Conditions for Self-Archiving.; This is not the published version. Please cite only the published version.; この論文は出版社版でありません。引用の際には出版社版をご確認ご 利用ください。 


\section{A novel constant-pressure irrigation technique for the treatment of renal pelvic tumors after ipsilateral ureterectomy}

Kenji Nakamura, Naoki Terada, Yoshio Sugino, Toshinori Yamasaki, Yoshiyuki Matsui, Masaaki Imamura, Kazutoshi Okubo, Tomomi Kamba, Koji Yoshimura, Osamu Ogawa

Department of Urology, Kyoto University Graduate School of Medicine, Kyoto, Japan

Author for correspondence and reprint requests:

Osamu Ogawa MD,PhD.

Department of Urology, Kyoto University Graduate School of Medicine 54 Shogoinkawahara-cho, Sakyo-ku, Kyoto, Japan

Phone: +81-75-751-3337

Fax: +81-75-751-3740

E-mail: kenji924@kuhp.kyoto-u.ac.jp

Running title: Constant-pressure irrigation technique
Abbreviations:
CIS $=$ carcinoma in situ
$\mathrm{CECT}=$ contrast ${ }^{-e n h a n c e d ~ c o m p u t e d ~ t o m o g r a p h y ~}$

\section{$\underline{\text { Key words }}$}

Pelvic Neoplasms; Instillation, Drug; Nephrostomy, Percutaneous; Mitomycin 


\section{$\underline{\text { Abstract }}$}

We herein report a case of a renal pelvic tumor that developed in the residual left renal pelvis after right nephroureterectomy, left ureterectomy, and total cystectomy in a patient with multiple urothelial tumors. The tumor was endoscopically ablated via a nephrostomy tract, and mitomycin $\mathrm{C}$ irrigation was performed. We designed a novel constant-pressure irrigation system for effective and safe irrigation into the closed space of the renal pelvis. We created a hole in the urine bag tube, inserted a 5-F open-end ureteral catheter via the hole, and kept the tip of the catheter at the end of the nephrostomy tube. The urine bag tube was placed $20 \mathrm{~cm}$ above the kidney level, and mitomycin $\mathrm{C}$ was continuously irrigated into the renal pelvis for 1 hour. Six weekly treatments were performed, and tumor recurrence was not identified for 1 year.

\section{$\underline{\text { Introduction }}$}

Nephroureterectomy with open excision of the bladder cuff remains the gold standard treatment for upper urinary tract urothelial carcinoma ${ }^{1}$. However, because of concerns about preservation of renal function or the inability of 
patients to tolerate surgery, a select group of patients may be suitable for organ-preserving treatment.

We herein present a novel constant-pressure irrigation technique. Because this irrigation system would allow for the increased performance of organ-preserving treatment, general urologists will find this manuscript very useful.

\section{$\underline{\text { Methods }}$}

A 63-year-old man had undergone four transurethral resections for the treatment of superficial bladder tumors from 2007 to 2009. Histological examinations revealed grade $2 \mathrm{pT} 1$ tumors together with carcinoma in situ (CIS). He didn't have any risk factors of multifocal urothelial carcinoma, such as smoking. In 2009, right renal pelvic tumors, left lower ureteral tumors, and bladder CIS were found by contrast-enhanced computed tomography (CECT) and cystoscopy. Total cystectomy and bilateral nephroureterectomy were recommended. However, the patient refused this treatment option because of his strong desire to avoid hemodialysis. Therefore, right nephroureterectomy, left ureterectomy, total cystectomy, and 
left nephrostomy were performed. Histological examination revealed grade 2 pT3 papillary urothelial carcinoma in the right renal pelvis and grade 2 $\mathrm{pTa}$ /is papillary urothelial carcinoma in the left ureter and the bladder, and combination chemotherapy using methotrexate, epirubicin, and cisplatin was performed. After 2 years of follow-up, the patient's urinary cytology result was positive, and a solitary left renal pelvic tumor was found by CECT. The tumor was endoscopically ablated using a 22-F flexible cystoscope. Histological examination revealed grade 2 pTa papillary urothelial carcinoma. A 22-F nephrostomy tube was inserted after the surgery, and adjuvant mitomycin $\mathrm{C}$ irrigation into the residual renal pelvis via the nephrostomy tube was scheduled. Because the renal pelvis was a closed space after the ipsilateral ureterectomy, an irrigation catheter was essential for safe and effective treatment. However, to our knowledge, no appropriate catheter is available, such as a three-way Foley catheter for bladder irrigation. Therefore, we created a novel constant-pressure irrigation system using a nephrostomy catheter, urine bag, and open-end ureteral catheter (Figure 1).

Our technique for mitomycin $\mathrm{C}$ irrigation was performed with the patient in 
the supine position. A small hole was made in the middle of the urine bag tube, and a 5-Fr open-end ureteral catheter was inserted into the hole. Using the fluoroscope, the tip of the ureteral catheter was kept at the end of the nephrostomy catheter. At first, contrast media was irrigated at $100 \mathrm{ml} / \mathrm{h}$, and we fluoroscopically confirmed that the renal pelvis was perfused by the contrast media. To maintain a constant pressure in the renal pelvis, the distance between the kidney and the urine bag tube was kept at $20 \mathrm{~cm}$. Under these conditions, renal pelvic irrigation was performed using mitomycin C. A bottle of $40 \mathrm{mg}$ mitomycin C dissolved in $100 \mathrm{ml}$ of $0.9 \%$ saline was irrigated via the ureteral catheter for 1 hour (Figure 2). Six weekly treatments were performed. The serum creatinine concentration was 1.3 to $1.5 \mathrm{mg} / \mathrm{dl}$ during the treatment period and $1.3 \mathrm{mg} / \mathrm{dl} 1$ year after treatment. One year after the treatment, no recurrence or metastasis was identified.

\section{Discussion}

Instillation therapy can be accomplished in several ways. Accepted techniques include antegrade instillation through a nephrostomy tube ${ }^{2}$ and 
retrograde instillation directly into a ureteral catheter ${ }^{3}$ or by reflux through an indwelling ureteral stent or iatrogenically created vesicoureteral reflux ${ }^{4,5}$. Patel described a convenient technique of outpatient instillation through a ureteral catheter placed suprapubically ${ }^{6}$.

The role of intravesical immunotherapy using bacillus Calmette-Guerin (BCG) or chemotherapy using mitomycin $\mathrm{C}$ for non-muscle-invasive urothelial carcinoma of the bladder has been established. However, the role of instillation therapy for upper urinary tract tumors has been equivocal, and its long-term effectiveness has not been elucidated ${ }^{7}$.

To the best of our knowledge, this is the first reported case of creation of an irrigation technique for the treatment of renal pelvic tumors in a solitary kidney after ipsilateral ureterectomy. The advantages of this technique are (1) the application of constant low pressure to minimize the risk of bacterial sepsis or systemic absorption of the agent, (2) contact of all urothelium with instillation media, (3) ability to repeat instillation therapy at low cost, and (4) safety of collecting the instillation media in the bag. It was considered that some selected multiple urothelial cancer patients might have chance to avoid bilateral nephrouretectomy using this technique. 


\section{$\underline{\text { References }}$}

1. Rouprêt M, Zigeuner R, Palou J et al. European guidelines for the diagnosis and management of upper urinary tract urothelial cell carcinomas: 2011 update. Eur Urol. 2011; 59: 584-594

2. Studer UE, Casanovaa G, Kraft R, Zingg EJ. Percutaneous bacillus Calmette-Guerin perfusion of the upper urinary tract for carcinoma in situ. J Urol. 1989; 142: 975-7

3. Sharpe JR, Duffy G and Chin JL. Intrarenal bacillus Calmette-Guerin therapy for upper urinary tract carcinoma in situ. $J$ Urol. 1993; 149: $457-460$

4. Herr HW. Durable response of carcinoma in situ of the renal pelvis to topical bacillus Calmette-Guerin. J Urol. 1985; 134: 531-2

5. Mukamel E, Vilkovsky E, Hadar H et al. The effect of intravesical bacillus Calmette-Guerin therapy on the upper urinary tract. $J$ Urol. 1991; 149: 980

6. Patel A, Fuchs GJ. New techniques for the administration of topical adjuvant therapy after endoscopic ablation of upper urinary tract transitional cell carcinoma. J Urol. 1998; 159: 71-5. 
7. Nepple KG, Joudi FN, O'Donnell MA. Review of topical treatment of upper tract urothelial carcinoma. Adv. Urol. 2009; 472831 


\section{Figure legends}

Figure 1. Constant-pressure renal pelvis irrigation system

Figure 2. Irrigation technique

A) Make a small hole in the urine bag tube and insert a 5-Fr open-end ureteral catheter into the hole

B) Keep the tip of the ureteral catheter at the end of the nephrostomy catheter

C) Place the urine bag tube $20 \mathrm{~cm}$ above the kidney and irrigate at $100 \mathrm{ml} / \mathrm{h}$ 
Figure 1

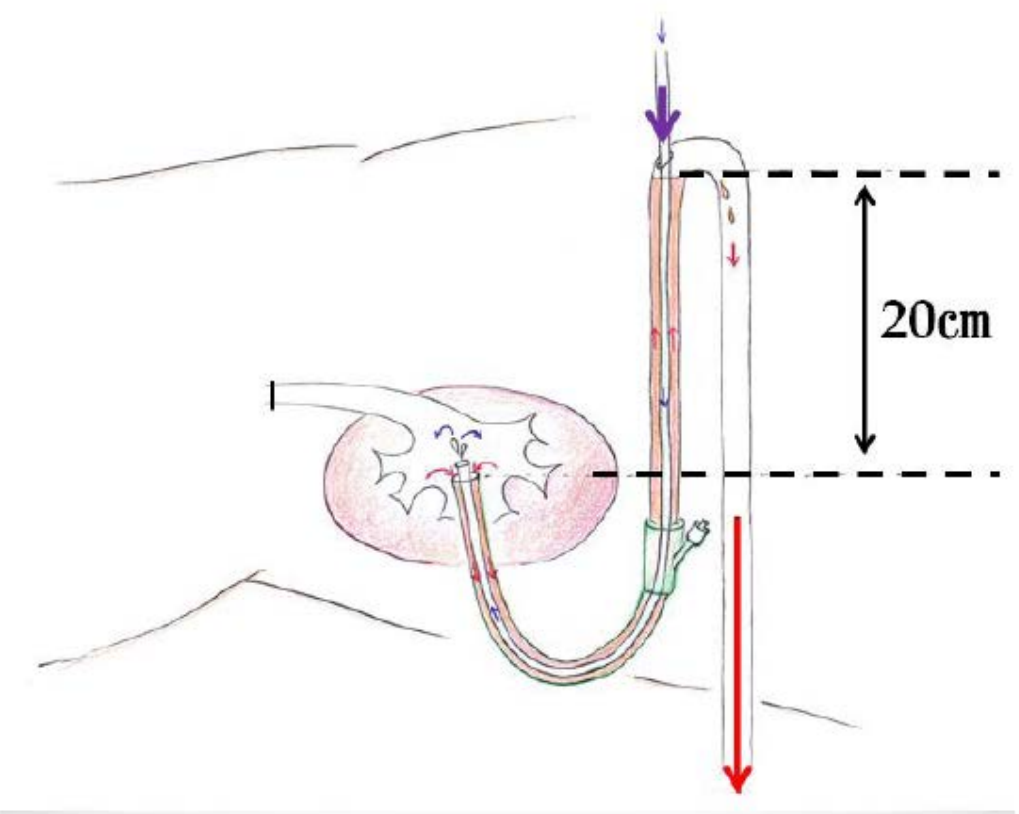

Figure 2

A

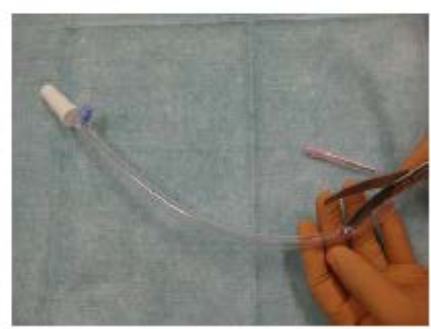

B

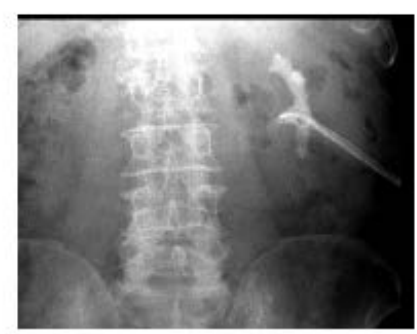

C

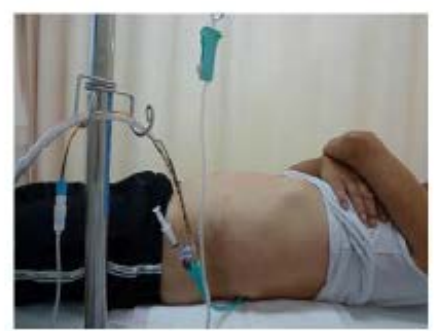

